VANESSA FONSECA VILAS BOAS

\title{
EFEITO DA TRIIODOTIRONINA (T3) E DO AGONISTA TR $\beta$ \\ SELETIVO GC-24 SOBRE O TROFISMO MUSCULAR \\ ESQUELÉTICO DE RATOS: ASPECTOS ENVOLVENDO A \\ PROTEÓLISE DEPENDENTE DE PROTEASSOMA
}

\begin{abstract}
Dissertação apresentada ao Programa de Biologia Celular e do Desenvolvimento do Instituto de Ciências Biomédicas da Universidade de São Paulo, para obtenção do Título de Mestre em Ciências.
\end{abstract}

Área de concentração:
Biologia Celular e do
Desenvolvimento

Orientador: Prof. Dr. Anselmo Sigari Moriscot 


\section{RESUMO}

VILAS BOAS, V.F. Efeito da triiodotironina (T3) e do agonista TR $\beta$ seletivo GC24 sobre o trofismo muscular esquelético de ratos: aspectos envolvendo a proteólise dependente de proteassoma. 2008. 107 folhas. Dissertação (Mestrado em Biologia Celular e do Desenvolvimento) - Instituto de Ciências Biomédicas, Universidade de São Paulo, São Paulo.

A triiodotironina (T3) exerce um importante papel em diversas funções teciduais através da sua ligação aos seus receptores específicos (TRs), os quais possuem 2 isoformas (TRa e TRß). Algumas alterações na função do músculo esquelético têm sido associadas a elevados níveis de T3, sendo a sarcopenia (perda de sarcômeros)

uma das principais anormalidades observadas no hipertiroidismo. Apesar do fenômeno da sarcopenia induzida por T3 já ter sido amplamente relatado, pouco ainda se sabe sobre os mecanismos moleculares envolvidos na proteólise induzida pela T3. Neste estudo investigamos o efeito da T3 e do seu análogo GC-24, um agonista TR $\beta$ seletivo, sobre a proteólise dependente do sistema Ubiquitina proteassoma. Analisamos o efeito de ambos, T3 e GC-24, sobre o trofismo muscular radial, nível de proteínas ubiquitinadas e expressão de alguns genes envolvidos na via ubiquitina proteassoma, que são importantes reguladores da proteólise muscular no músculo esquelético. Para tanto, ratos Wistar machos (170-200g) receberam T3 $(30 \mu \mathrm{g} / 100 \mathrm{~g})$ e doses equimolares de GC-24 (16 $\mu \mathrm{g} / 100 \mathrm{~g})$ por $12 \mathrm{hs}$, $24 \mathrm{hs}$ e 1 semana. Ao término do tratamento, os animais foram sacrificados e os músculos sóleo e extensor longo dos dedos (EDL) foram removidos para análise histológica através da área de secção transversa, análise da expressão protéica através de Western Blot e expressão gênica por Reação em Cadeia da Polimerase (PCR) em tempo real. Foram estudadas as ligases proteína-ubiquitina (Atrogin-1, MuRF-1 e E3a) e as enzimas de desubiquitinação (UBP45, UBP69 e USP28). T3 e GC-24 
promoveram redução do diâmetro das fibras musculares em relação ao grupo Controle em todos os períodos avaliados. Ambos aumentaram o nível de proteínas ubiquitinadas, tanto no sóleo quanto no EDL. Em relação à expressão gênica, T3 e GC-24 modularam a expressão dos genes analisados de maneira diferenciada. No músculo sóleo, T3 aumentou a expressão gênica de Atrogin-1 e E3a, mas não alterou a expressão gênica de MuRF-1. Por outro lado, no músculo EDL, a expressão gênica de Atrogin-1 não foi alterada, enquanto as expressões gênicas de E3a e de MuRF-1 foram elevadas pela. Em ambos os músculos a expressão gênica das enzimas de desubiquitinação não foi, em geral, modulada pela T3, com exceção de UBP45, que foi reduzida no músculo sóleo. GC-24 aumentou a expressão gênica de E3a e MuRF-1 no músculo sóleo, enquanto a expressão gênica de Atrogin-1 não foi alterada. Porém, no músculo EDL, GC-24 aumentou a expressão gênica de Atrogin-1 e E3a e não alterou a expressão de MuRF-1. Finalmente, GC-24 reduziu a expressão gênica de UBP45 no EDL e aumentou e a expressão gênica de USP28 em ambos os músculos. Estes dados sugerem que tanto T3 quanto GC-24 são capazes de modular a proteólise muscular.

Palavras-chave: Hormônio tireoideano, músculo esquelético, ubiquitina, ligase ubiquitina-proteína, enzimas de desubiquitinação, proteólise. 


\section{ABSTRACT}

VILAS BOAS, V.F Effect of the Triiodothyronine (T3) and the Thyroid Receptor Beta selective Agonist GC-24 upon rat skeletal muscle trophism: expression of proteasome-dependent genes. 2008. 107 folhas. Dissertação (Mestrado em Biologia Celular e do Desenvolvimento) - Instituto de Ciências Biomédicas, Universidade de São Paulo, São Paulo.

Triiodothyronine (T3) is known to play a key role in the function of several tissues/organs via the thyroid hormone receptor isoforms alpha (TRa) and beta (TR $\beta$ ). Abnormalities in skeletal muscle function have been associated with increased levels of T3, which is a major sarcopenia (loss of sarcomeres). Although the phenomenon of sarcopenia induced by T3 has been widely reported, little is known about the molecular mechanisms involved in proteolysis induced by T3. In this study we have investigated the effects of T3 and GC-24, a novel synthetic TR $\beta$ selective compound, on the ubiquitin proteasome pathway. We analyzed the effect of T3 and GC-24 on the radial trophism, ubiquitination levels and gene expression of the ubiquitin-proteasome pathway, which are important regulators of muscle proteolysis in the skeletal muscle. We have addressed the ubiquitin ligases (Atrogin1, MuRF-1 and E3 $\alpha$ ) and the deubiquitinating enzymes (UBP45, UBP69 and USP28). Wistar male rats (170-200g) were divided in 4 groups (Control, 12, 1 and 7 days). Rats received T3 $(30 \mu \mathrm{g} / 100 \mathrm{~g})$ and GC-24 (16 $\mu \mathrm{g} / 100 \mathrm{~g})$. After decapitation, EDL and soleus muscles were removed for histological analysis, protein expression and gene expression. Cross sectional area was determined in histological sections through the software "Image-Pro Plus. The ubiquitination levels was determined by Western Blot and gene expression determined by Real Time PCR analysis. T3 and GC-24 reduced the diameter of the muscle fibers vs control group. Both T3 and GC-24 incresed the ubiquitination levels, in the soleus and EDL. Regarding gene expression 
analysis, T3 and GC-24 modulate the gene expression in a differential manner. In the soleus, T3 increased Atrogin-1 and E3 alpha gene expression, while did not alter Murf-1 gene expression. On the other hand, in EDL Atrogin-1 gene expression is not altered, while E3 alpha and Murf-1 are elevated by T3. In the soleus and EDL deubiquitinating gene expression is mostly not altered, exception made for UBP 45 , which is reduced by T3 in soleus muscle. GC-24, increased gene expression of E3a and MuRF-1 in the soleus, while did not alter Atrogin-1 gene expression. However, in EDL muscle, GC-24 increased Atrogin-1 and E3a mRNA, while did not alter MuRF-1. Finally, GC-24 decreased UBP 45 gene expression in EDL muscle and USP 28 gene expression was robustly elevated by GC-24 in both muscles analyzed. This data shows that GC-24 is able to strongly modulate genes that are less responsive or even unresponsive to $\mathrm{T} 3$, pointing that the GC-24-TRb complex might trans-activate differently target genes. However, both T3 and GC-24 are able to modulate the muscle proteolysis.

Key words: Thyroid hormone; muscle; ubiquitin, ubiquitin ligase; deubiquitinating enzyme and proteolysis. 
1 INTRODUÇÃO 


\subsection{Hormônio Tireoideano}

O hormônio tireoideano (Triiodotironina, T3) desempenha um papel importante no desenvolvimento, diferenciação e metabolismo de vertebrados e é requerido por todos os tecidos para manutenção das funções celulares (ZHANG E LAZAR, 2000). Muitos efeitos da T3 são mediados por receptores nucleares de alta afinidade, conhecidos como receptores do hormônio tireoideano (TRs), codificados por dois genes: o gene TR $\alpha$ (C-erbA- $\alpha)$ e o gene TR $\beta$ (C-erbA- $\beta)$ (LAZAR, 1993).

As isoformas de TR, como descritas anteriormente, são codificadas por 2 genes (YEN, 2001). O gene TR $\alpha$ codifica as variantes TR $\alpha 1$ e TR $\alpha 2$, sendo que a última não se liga ao T3 e atua, pelo menos in vitro, como um antagonista das isoformas funcionais (KATZ e LAZAR, 1993). O gene TR $\beta$ codifica 3 isoformas funcionais - TR $\beta 1$, TR $\beta 2$ e TR $\beta 3$ - e uma isoforma truncada denominada de TR $\Delta \beta 3$ (WILLIAMS, 2000). Quanto à distribuição tecidual dos TRs, estes são expressos virtualmente em todos os tecidos, embora a distribuição seja heterogênea. TRa1 é predominantemente expresso no músculo esquelético, tecido adiposo marrom (MITSUHASHI et al., 1988), tecido cardíaco (GLOSS et al., 2001), cerebelo e tecido ósseo (FORREST et al., 1996; WILLIAMS et al., 1994). TRa2 é muito expresso no cérebro (MITSUHASHI e NIKODEM, 1989) e também é encontrado no tecido muscular esquelético e cardíaco, testículos, rins e tecido adiposos marrom (HODIN et al., 1990; MITSUHASHI e NIKODEM, 1989). TRß1 é a isoforma mais homogeneamente distribuída; porém, é encontrada em altas concentrações no cérebro, fígado e rins (HODIN et al., 1990) A isoforma TRß2 é encontrada quase que exclusivamente no eixo hipotálamo/hipófise e no sistema nervoso central (HODIN et al., 1990). A isoforma TR $\beta 3$, ainda pouco estudada, possui uma 
distribuição homogênea nos tecidos. Considerando as diferentes isoformas de TR e sua complexidade de ação, é fundamental estudar o papel biológico dos TRs.

Estruturalmente, estes receptores apresentam uma extremidade aminoterminal ( $\mathrm{NH} 2$ ) seguida pelos domínios $\mathrm{A} / \mathrm{B}, \mathrm{C}, \mathrm{D}, \mathrm{E} / \mathrm{F}$ e, por fim, uma extremidade carboxi-terminal $(\mathrm{COOH})$. A região $\mathrm{C}$ ou domínio de ligação do DNA (DNA-binding domains, DBD) tem habilidade de reconhecer seqüências alvo específicas e ativar genes. O domínio D une os domínios DBD e LBD (domínio de ligação do ligante ou Ligand Binding Domain)(ARANDA e PASCUAL, 2001; ECKEY et al., 2003) e, finalmente o domínio $\mathrm{E} / \mathrm{F}$ (LBD), um domínio multifuncional que, além de promover a ligação do receptor ao seu ligante, pode mediar a dimerização e modular a atividade transcricional dependente do ligante. Esta região está disposta no formato de um bolso para receber o ligante (ECKEY et al., 2003; LAZAR, 1993).

Os TRs atuam como repressores ou ativadores da transcrição gênica, ou seja, regulam a expressão do gene alvo, tanto na presença quanto na ausência do seu ligante, a T3 (ECKEY et al., 2003; GLASS, 1994). Para que essa regulação ocorra é necessário que o TR, através do DBD, ligue-se com alta afinidade a regiões específicas do gene alvo. Estas regiões do DNA reconhecidas pelos TRs recebem o nome de elementos responsivos ao receptor do hormônio tireoideano (TREs) (BASSETT et al., 2003; GLASS, 1994; WILLIAMS et al., 1994). Os TRs se ligam predominantemente como heterodímeros, ou seja, associados a outros receptores nucleares. Os principais receptores nucleares que se associam ao TR para formar heterodímeros são os receptores de ácido retinóico (RXR e RAR) e receptores de Vitamina D (VDR), sendo a ligação mais forte com RXR. A ligação do TR em forma de monômero ou homodímero também pode ocorrer, porém, é relativamente fraca, levando a uma rápida dissociação do complexo TR-TRE (BASSETT et al., 2003; 
GLASS, 1994; WILLIAMS et al., 1994). Os TREs podem ser classificados como positivos (pTRE) quando o complexo T3-TR-TRE induz a transcrição gênica, ou negativos (nTRE), quando este complexo inibe a transcrição gênica (ECKEY et al., 2003).

Além da formação do complexo T3-TR-TRE, proteínas co-reguladoras participam do processo de regulação da transcrição gênica. Desta forma, o complexo pode interagir com co-ativadores e co-repressores (BASSETT et al., 2003). A modulação do complexo de pré-inicialização por ativadores transcricionais envolve não somente uma ação direta, mas também componentes de ações indiretas da maquinaria de transcrição basal. Os co-repressores podem se ligar a ativadores transcricionais e inibir a formação de um complexo transcricional ativo. Os co-repressores classicamente conhecidos são SMRT (silencing mediator for RAR and TR) e NCoR (nuclear receptor co-repressor). Ambos apresentam estrutura e função muito semelhantes, promovendo a deacetilação de histonas no nucleossomo, tornando a cromatina condensada e, portanto, inviável para o acoplamento da maquinaria transcricional (BASSETT et al., 2003; ECKEY et al., 2003). A ligação do hormônio promove a dissociação dos co-repressores e o recrutamento de coativadores, que por sua vez remodelam a cromatina fazendo com que a mesma se torne permissiva a fatores de transcrição (ECKEY et al., 2003). Um co-ativador de TR é o SRC-1 (Steroid receptor coactivator-1), que possui atividade acetiltransferase sobre as histonas (histone acetyl transferase - HAT). Esta atividade pode fazer com que os nucleossomos fiquem descondensados e conseqüentemente expõe o DNA a fatores de transcrição. Além disso, SRC-1 também atua como uma proteína adaptadora para a RNA polimerase II e para as demais proteínas envolvidas na regulação gênica basal. Um outro grupo de co-ativadores são as 
TRAPs (TR associated proteins), que também promovem a ligação da RNA polimerase II ao DNA. A existência destes dois co-ativadores sugere uma ação coordenada, onde inicialmente atua a SRC-1, com sua atividade HAT, e posteriormente as TRAPs, servindo de âncora para toda maquinaria transcricional (BASSETT et al., 2003; MOORE e GUY, 2005).

\subsection{Agonistas TR $\beta$ seletivo}

Nos últimos anos, uma série de agonistas e antagonistas seletivos para TR $\beta$ estão em desenvolvimento para uso como agente terapêutico e também como ferramentas farmacológicas para investigar o papel dos TRs in vivo e in vitro. O primeiro agonista TR $\beta$ desenvolvido foi denominado GC-1. Neste composto, basicamente todos os iodos da T3 são substituídos por grupos metil e isopropil (CHIELLINI et al., 1998). O GC-1 apresenta a mesma afinidade pelo TR $\beta$ quando comparado à T3, e dez vezes menos afinidade pelo TR $\alpha$ (CHIELLINI et al., 1998).

Recentemente um novo membro da série GC, denominado de GC-24, foi desenvolvido. Este composto também possui a mesma afinidade para o TR $\beta$, quando comparado à T3, e cem vezes menor afinidade pelo TR $\alpha$. É, portanto, um agonista TR $\beta$ dez vezes mais específico quando comparado ao GC-1 (BORNGRAEBER et al., 2003).

A estrutura cristalográfica do TR $\beta$ complexado com GC-1 demonstrou que esta especificidade se dá pela interação da extremidade carboxi-terminal do GC-1 com a porção polar do domínio de ligação do hormônio, especificamente com um resíduo de Arg272, que não é conservado no TRa (substituído pela Ser227 na posição equivalente ao resíduo de Arg272). Entretanto, um único aminoácido difere os subtipos de TR para assim possibilitar a seletividade do GC-1. Substituições 
químicas foram devidamente associadas ao GC-1, incluindo um grande anel fenol na posição 3' do primeiro anel. Essa modificação promoveu maior seletividade, mantendo a afinidade de ligação normal e também a função do receptor. Após essas modificações o composto foi denominado GC-24, que associado ao TR $\beta$ revela um novo modo de adaptação. O interior da região LBD se abre para acomodar o anel fenol. Mostrando que a colocação de extensões nos agonistas destaca áreas de flexibilidade dentro dos LBDs, que poderiam acomodar as extensões, reforçando assim a seletividade dos agonistas (BORNGRAEBER et al., 2003; TOGASHI et al., 2005).

\subsection{Ações biológicas da T3}

O Hormônio tireoideano tem certas ações biológicas que são atrativas como agente terapêutico no tratamento de dislipidemias e obesidade. Em doses supra fisiológicas este hormônio induz uma rápida e significativa redução do peso corporal (Krotkiewski, 2002) e também a uma redução dos níveis plasmáticos de colesterol e triglicérides (Pucci et al., 2000). Por outro lado, T3 também promove hipertrofia cardíaca concêntrica e taquicardia (BIONDI et al., 2002; KLEIN e OJAMAA, 2001), além de perda de massa óssea (Fallon et al., 1983; Gouveia, 2004). No tecido muscular esquelético, este hormônio converte a miosina de cadeia pesada I (MHC I) para $\mathrm{MHC} 2 \mathrm{~B}$, modificando assim o tipo de fibra muscular (tipo I para tipo II) (MIYABARA et al., 2005; VADASZOVA et al., 2004), além de promover uma severa proteólise com conseqüente perda de massa e força muscular esquelética (EVERTS et al., 1987; VADASZOVA et al., 2004) 45, 46).

Como mencionado anteriormente, compostos da série GC podem ser usados para promover ações biológicas específicas ao TRß (tais como redução dos níveis 
plasmáticos de colesterol e triglicérides) tão eficientes quanto T3 (JOHANSSON et al., 2005; TROST et al., 2000), além de promover aumento do metabolismo (BAXTER et al., 2004). Diferentemente da T3, o GC-1 não promove alterações cardíacas como hipertrofia e aumento da freqüência cardíaca (Trost et al., 2000) e também não causa perda de massa óssea (FREITAS et al., 2003). Segundo Miyabara (2005), o GC-24 não promove transição do tipo de fibra muscular (Tipo I para tipo II), mas reduz a área de secção transversa (diâmetro) das fibras musculares do tipo I no músculo extensor longo dos dedos (EDL).

Embora o GC-24 não altere o tipo de fibra muscular, ainda não está claro se este composto modula a atrofia muscular, como mencionado anteriormente, uma condição causada pela T3, que leva à perda de força muscular e assim compromete as atividades diárias do indivíduo. A atrofia muscular pode ser definida como redução da área de secção transversa ou comprimento da fibra muscular, ou ambos. Pode também pode ocorrer uma redução da massa muscular esquelética, conteúdo protéico ou redução do número de fibras, e redução da força muscular (CZERWINSKI et al., 1989).

\subsection{Via Ubiquitina Proteassoma}

É bem estabelecido que o sistema Ubiquitina Proteassoma é um dos sistemas mais importantes na proteólise muscular (LECKER et al., 1999; MITCH e GOLDBERG, 1996; TAWA et al., 1997). Tem sido demonstrado que a T3 aumenta a produção de ATP e conseqüentemente ativa o proteassoma, aumentando a proteólise miofibrilar em cultura primária de células musculares (BORNGRAEBER et al., 2003) (DOI et al., 2003), apesar dos mecanismos ainda não serem totalmente claros. 
O sistema proteolítico dependente de ATP e ubiquitina é formado por uma protease de peso molecular entre 1000 a $1500 \mathrm{KDa}$, composta por subunidades de 34-110 KDa e com um coeficiente de sedimentação de 26S, daí a sugestão da denominação mais aceita atualmente: proteassoma 26S. Este, por sua vez, é formado por um núcleo catalítico no formato de um cilindro oco - denominado proteassoma 20 S e dois complexos regulatórios 19S, nos quais na qual se localizam ATPases responsáveis pelo desenovelamento das proteínas a serem degradadas pelas atividades proteolíticas residentes em 20S. Os complexos regulatórios 19S, posicionados em ambas as extremidades do proteassoma 20S, são necessários para o reconhecimento específico de proteínas ubiquitinadas, seu desenovelamento e translocação para o interior da câmara catalítica.

Os substratos protéicos são marcados para degradação por uma ligação covalente a ubiquitina $(\mathrm{Ub})$. A ubiquitina é uma proteína de 76 resíduos de aminoácido expressa em todas as células eucarióticas, onde é sintetizada a partir de genes múltiplos como produto da fusão $\mathrm{N}$-terminal com outras proteínas ou oligômeros cabeça-cauda e clivada por peptidases que liberam mono-ubiquitinas. Cadeias poli-ubiquitina se formam a partir da adição de moléculas de ubiquitina ao resíduo de lisina-48 de uma outra molécula de ubiquitina. (KISSELEV et al., 1998).

A marcação do substrato a ser degradado ocorre através de uma cascata multi-enzimática na qual as enzimas se ligam por meio de ligações tiol-ésteres: inicialmente, ocorre a ativação da Ub pela enzima ativadora de ubiquitina (E1, 117KDa), que leva à formação de uma ligação tiol-éster entre o resíduo de cisteína de E1 e a extremidade carboxi-terminal da Ub. Esse passo envolve a formação de um adenilato de Ub intermediário, com concomitante hidrólise de ATP, e transferência da Ub ativada para o centro tiol da enzima E1, com liberação de AMP. 
Em seguida, ocorre uma transacilação para um resíduo de cisteína de E2 (enzima conjugadora de ubiquitina). Os ésteres de tiol, formados entre E2 e Ub, são doadores da Ub para formação da ligação isopeptídica entre o resíduo de glicina do terminal $\mathrm{C}$ da Ub e grupos de amina de resíduos de lisina das proteínas-substrato. Este passo requer a participação de ligases de ubiquitina-proteína (E3), responsáveis pela seleção da proteína substrato através do reconhecimento de um sinal de degradação existente nessa proteína. Várias moléculas de Ub podem ser adicionadas formando uma cadeia multi-ubiquitina. (ATTAIX et al., 2002; HERSHKO e CIECHANOVER, 1998). Os substratos protéicos ubiquitinados devem estar desenovelados, a fim de penetrar na subunidade catalítica do proteassoma $26 \mathrm{~S}$. Isso se faz à custa da energia produzida pela hidrólise de ATP por ATPases presentes na subunidade regulatória 19S, que regula a abertura deste canal (HERSHKO e CIECHANOVER, 1998).

Diferentemente das enzimas E1 e E2, a expressão gênica das E3 é altamente modulada em condições de perda muscular muscular, como desuso, desnutrição (GOMES et al., 2001) (MEDINA et al., 1991), imobilização, sepse (Tiao et al., 1996), grandes queimaduras, hipertireoidismo (KETTELHUT et al., 1988; Solomon e Goldberg, 1996; Tawa et al., 1997), desnervação (MEDINA et al., 1991)(WING et al, 1995) e hipogravidade, entre outras (BODINE et al., 2001; FISCHER et al., 2000; GOMES et al., 2001; LECKER et al., 2004, NURY et al, 2007). Estudos têm demonstrado que a expressão de genes codificados por E3, tais como Muscle Ring Finger 1 (MuRF-1), Muscle Atrophy F-box (MAFbx ou Atrogin-1) e E3 Alpha/UBR1 (E3a) está aumentada nestes modelos de atrofia muscular. E3a foi a primeira E3 implicada em processos de atrofia muscular (SOLOMON e GOLDBERG, 1996). A 
mesma é responsável por aumentar as taxas de ubiquitinação de proteínas de meia vida curta ( $N$-end rule) encontradas em músculos que estão em processo de atrofia.

Animais knockout para E3a, MAFbx e MuRF-1 (E3a/ UBR1 ${ }^{-/}$, MAFbx ${ }^{-/}$e MuRF-1 $1^{-/-}$) têm sido gerados (BODINE et al., 2001). Em condições normais esses animais são fenotipicamente idênticos aos animais selvagens. Após desnervação muscular ou desnutrição a perda de massa muscular é significativamente menor nos animais E3a/ UBR $1^{-/}, \quad$ MAFbx ${ }^{-/}$e MuRF-1/- em comparação aos animais desnutridos ou desnervados do grupo Controle (BODINE et al., 2001; KWON et al, 2001).

\subsubsection{Desubiquitinação}

A conjugação da molécula de ubiquitina a uma proteína alvo específica é um processo reversível, pois enzimas de desubiquitinação (DUB) são capazes de remover a Ub do substrato protéico e livrar a proteína da degradação. Entretanto, as moléculas de Ub não são degradadas e sim constantemente recicladas através da ação de hidrolases de cisteína específicas. Estas enzimas são responsáveis por reciclar ubiquitina de cadeias multi-ubiquitina conjugadas com proteína-substrato e manter o proteassoma livre. As DUBs podem ser agrupadas com base na homologia de sua seqüência em duas classes bem definidas: hidrolases do terminal $\mathrm{C}$ da ubiquitina (ubiquitin carboxy-terminal hydrolases - UCH) e proteases de processamento específicas para ubiquitina (ubiquitin processing proteases - UBPs, também conhecidas como ubiquitin specific proteases - USPs) (Fischer, 2003; Wilkinson, 2000). As UBPs são responsáveis pela clivagem dos precursores de ubiquitina e de cadeias poli-ubiquitina, gerando $\mathrm{Ub}$ livre; enquanto as $\mathrm{UCH}$ hidrolisam ligações éster e amida de pequenos aductos ligados ao terminal C da Ub 
(AMERIK e HOCHSTRASSER, 2004). O aumento da expressão das enzimas de desubiquitinação está associado ao aumento da proteólise muscular e implica a regulação de genes envolvidos no sistema Ub-proteassoma, tais com UBP45, UBP69 e USP28 (COMBARET et al, 2004). USP28 é preferencialmente expressa no músculo esquelético e cardíaco e UBP45 e UBP69 estão envolvidas na regulação da diferenciação de células musculares (PARK et al, 2002). 
6 CONCLUSÕES 
T3 e GC-24 promoveram a redução do diâmetro das fibras musculares em relação ao grupo Controle em todos os períodos avaliados. Ambos aumentaram o nível de proteínas ubiquitinadas, tanto no osso sóleo quanto no EDL.

Em relação à expressão gênica, T3 e GC-24 modularam a expressão dos genes analisados de maneira diferenciada. Esses dados sugerem que GC-24 é capaz de modular genes que são pouco responsivos ou não responsivos à T3, apontando que o complexo TRB/GC-24 pode transativar genes alvos.

Contudo, tanto T3 quanto GC-24 são capazes de modular a proteólise muscular. 
REFERÊNCIAS BIBLIOGRÁFICAS 
AMERIK, A.; HOCHSTRASSER; M. Mechanism and function of deubiquitinating enzymes. Biochim. Biophys. Acta., v. 29, n.1695 (1-3), p.189-207, 2004.

ARANDA, A.; PASCUAL, A. Nuclear hormone receptors and gene expression. Physiol. Rev., v.81, n.3, p.1269-1304, 2001.

ATTAIX, D.; COMBARET, L.; TAILLANDIER, D.; BECHET, D. Regulation of ubiquitin-proteasome dependent muscular proteolysis by hormones and nutrients. J. Annu. Diabetol. Hotel Dieu, p.123-133, 2002.

BASSETT, J. H.; HARVEY, C. B.; WILLIAMS, G. R. Mechanisms of thyroid hormone receptor-specific nuclear and extra nuclear actions. Mol. Cell. Endocrinol., v.213, n.1, p.1-11, 2003.

BAXTER, J. D.; WEBB, P.; GROVER, G.; SCANLAN, T. S. Selective activation of thyroid hormone signaling pathways by GC-1: a new approach to controlling cholesterol and body weight. Trends. Endocrinol. Metab., v.15, n.4, p.154-157, 2004.

BIONDI, B.; PALMIERI, E. A.; LOMBARDI, G.; FAZIO, S. Effects of thyroid hormone on cardiac function: the relative importance of heart rate, loading conditions, and myocardial contractility in the regulation of cardiac performance in human hyperthyroidism. J. Clin. Endocrinol. Metab., v.87, n.3, p.968-974, 2002.

BODINE, S. C.; LATRES, E.; BAUMHUETER, S.; LAI, V. K.; NUNEZ, L.; CLARKE, B. A.; POUEYMIROU, W. T.; PANARO, F. J.; NA, E.; DHARMARAJAN, K.; PAN, Z. Q.; VALENZUELA, D. M.; DECHIARA, T. M.; STITT, T. N.; YANCOPOULOS, G. D; GLASS, D. J. Identification of ubiquitin ligases required for skeletal muscle atrophy. Science, v.294, n.5547, p.1704-1708, 2001.

BORNGRAEBER, S.; BUDNY, M. J.; CHIELLINI, G.; CUNHA-LIMA, S. T.; TOGASHI, M.; WEBB, P.; BAXTER, J. D.; SCANLAN, T. S.; FLETTERICK, R. J. Ligand selectivity by seeking hydrophobicity in thyroid hormone receptor. Proc. Natl. Acad. Sci. U S A, v.100, n.26, p.15358-15363, 2003.

BRADFORD, M. M. A rapid and sensitive method for the quantitation of microgram quantities of protein utilizing the principle of protein-dye binding. Anal. Biochem., v.72, p.248-254, 1976.

CHIELLINI, G.; APRILETTI, J. W.; YOSHIHARA, H. A.; BAXTER, J. D.; RIBEIRO, R. C.; SCANLAN, T. S. A high-affinity subtype-selective agonist ligand for the thyroid hormone receptor. Chem. Biol., v.5, n.6, p.299-306, 1998.

CZERWINSKI, S. M.; ZAK, R.; KUROWSKI, T. T.; FALDUTO, M. T.; HICKSON, R. C. Myosin heavy chain turnover and glucocorticoid deterrence by exercise in muscle. J. Appl. Physiol., v.67, n.6, p.2311-2315, 1989.

DERUISSEAU, K. C.; KAVAZIS, A. N.; DEERING, M. A.; FALK, D. J.; VAN GAMMEREN, D.; YIMLAMAI, T.; ORDWAY, G. A.; POWERS, S. K. Mechanical 
ventilation induces alterations of the ubiquitin-proteasome pathway in the diaphragm. J. Appl. Physiol., v.98, n.4, p.1314-1321, 2005.

DOI, J.; OHTSUBO, A.; OHTSUKA, A.; HAYASHI, K. Triiodothyronine but not thyroxine accelerates myofibrillar proteolysis via ATP production in cultured muscle cells. Biosci. Biotechnol. Biochem., v.67, n.11, p.2451-2454, 2003.

ECKEY, M.; MOEHREN, U.; BANIAHMAD, A. Gene silencing by the thyroid hormone receptor. Mol. Cell. Endocrinol., v.213, n.1, p.13-22, 2003.

EPPENBERGER-EBERHARDT, M.; AIGNER, S.; DONATH, M. Y.; KURER, V.; WALTHER, P.; ZUPPINGER, C.; SCHAUB, M. C.; EPPENBERGER, H. M. IGF-I and FGF differentially influence atrial natriuretic factor and alpha-smooth muscle actin expression in cultured atrial compared to ventricular adult rat cardiomyocytes. J. Mol. Cell. Cardiol., v.29, n.8, p.2027-2039, 1997.

EVERTS, M. E.; SIMONIDES, W. S.; LEIJENDEKKER, W. J.; VAN HARDEVELD, C. Fatigability and recovery of rat soleus muscle in hyperthyroidism. Metabolism., v.36, n.5, p.444-450, 1987.

FALLON, M. D.; PERRY, H. M.; BERGFELD, M.; DROKE, D.; TEITELBAUM, S. L; AVIOLI, L. V. Exogenous hyperthyroidism with osteoporosis. Arch. Intern. Med., v.143, n.3, p.442-444, 1983.

FISCHER, D.; SUN, X.; GANG, G.; PRITTS, T.; HASSELGREN, P. O. The gene expression of ubiquitin ligase E3alpha is upregulated in skeletal muscle during sepsis in rats-potential role of glucocorticoids. Biochem. Biophys. Res. Commun., v.267, n.2, p.504-508, 2000.

FISCHER, J. A. Deubiquitinating enzymes: their roles in development, differentiation, and disease. Int. Rev. Cytol., v.229, p.43-72, 2003.

FORREST, D.; HANEBUTH, E.; SMEYNE, R. J.; EVERDS, N.; STEWART, C. L.; WEHNER, J. M.; CURRAN, T. Recessive resistance to thyroid hormone in mice lacking thyroid hormone receptor beta: evidence for tissue-specific modulation of receptor function. Embo. J., v.15, n.12, p.3006-3015, 1996.

FREITAS, F. R.; MORISCOT, A. S.; JORGETTI, V.; SOARES, A. G.; PASSARELLI, M.; SCANLAN, T. S.; BRENT, G. A.; BIANCO, A. C.; GOUVEIA, C. H. Spared bone mass in rats treated with thyroid hormone receptor TR beta-selective compound GC1. Am. J. Physiol. Endocrinol. Metab., v.285, n.5, p.E1135-1141, 2003.

GLASS, C. K. Differential recognition of target genes by nuclear receptor monomers, dimers, and heterodimers. Endocr. Rev., v.15, n.3, p.391-407, 1994.

GLOSS, B.; GIANNOCCO, G.; SWANSON, E. A.; MORISCOT, A. S.; CHIELLINI, G.; SCANLAN, T.; BAXTER, J. D.; DILLMANN, W. H. Different configurations of specific thyroid hormone response elements mediate opposite effects of thyroid hormone and GC-1 on gene expression. Endocrinol., v.146, n.11, p.4926-4933, 2005. 
GLOSS, B.; TROST, S.; BLUHM, W.; SWANSON, E.; CLARK, R.; WINKFEIN, R.; JANZEN, K.; GILES, W.; CHASSANDE, O.; SAMARUT, J.; DILLMANN, W. Cardiac ion channel expression and contractile function in mice with deletion of thyroid hormone receptor alpha or beta. Endocrinol., v.142, n.2, p.544-550, 2001.

GOMES, M. D.; LECKER, S. H.; JAGOE, R. T.; NAVON, A.; GOLDBERG, A. L. Atrogin-1, a muscle-specific F-box protein highly expressed during muscle atrophy. Proc. Natl. Acad. Sci. U S A, v.98, n.25, p.14440-14445, 2001.

GOUVEIA, C. H. The molecular and structural effects of thyroid hormone in bones. Arq. Bras. Endocrinol. Metabol., v.48, n.1, p.183-195, 2004.

HERSHKO, A.; CIECHANOVER, A. The ubiquitin system. Annu. Rev. Biochem., v.67, p.425-479, 1998.

HODIN, R. A.; LAZAR, M. A.; CHIN, W. W. Differential and tissue-specific regulation of the multiple rat c-erbA messenger RNA species by thyroid hormone. J. Clin. Invest., v.85, n.1, p.101-105, 1990.

JOHANSSON, L.; RUDLING, M.; SCANLAN, T. S.; LUNDASEN, T.; WEBB, P.; BAXTER, J.; ANGELIN, B.; PARINI, P. Selective thyroid receptor modulation by GC1 reduces serum lipids and stimulates steps of reverse cholesterol transport in euthyroid mice. Proc. Natl. Acad. Sci. U S A, v.102, n.29, p.10297-10302, 2005.

KATZ, D.; LAZAR, M. A. Dominant negative activity of an endogenous thyroid hormone receptor variant (alpha 2) is due to competition for binding sites on target genes. J. Biol. Chem., v.268, n.28, p.20904-20910, 1993.

KETTELHUT, I. C.; WING, S. S.; GOLDBERG, A. L. Endocrine regulation of protein breakdown in skeletal muscle. Diabetes Metab. Rev., v.4, n.8, p.751-772, 1988.

KISSELEV, A. F.; AKOPIAN, T. N.; GOLDBERG, A. L. Range of sizes of peptide products generated during degradation of different proteins by archaeal proteasomes. J. Biol. Chem., v.273, n.4, p.1982-1989, 1998.

KLEIN, I.; OJAMAA, K. Thyroid hormone and the cardiovascular system. N. Engl. J. Med., v.344, n.7, p.501-509, 2001.

KWON, Y.T.; XIA, Z.; DAVYDOV, I.V.; LECKER, S.H. VARSHAVSKY, A. Construction and analysis of mouse strains lacking the ubiquitin ligase UBRI (E3alpha) of the N-end rule pathway. Mol. Cell. Biol. v. 21, p. 8007-8021.

KROTKIEWSKI, M. Thyroid hormones in the pathogenesis and treatment of obesity. Eur. J. Pharmacol., v.440, n.2-3, p.85-98, 2002.

LAZAR, M. A. Thyroid hormone receptors: multiple forms, multiple possibilities. Endocr. Rev., v.14, n.2, p.184-193, 1993.

LECKER, S. H.; JAGOE, R. T.; GILBERT, A.; GOMES, M.; BARACOS, V.; BAILEY, J.; PRICE, S. R.; MITCH, W. E. e GOLDBERG, A. L. Multiple types of skeletal 
muscle atrophy involve a common program of changes in gene expression. Faseb J., v.18, n.1, p.39-51, 2004.

LECKER, S. H.; SOLOMON, V.; PRICE, S. R.; KWON, Y. T. MITCH, W. E.; GOLDBERG, A. L. Ubiquitin conjugation by the $\mathrm{N}$-end rule pathway and mRNAs for its components increase in muscles of diabetic rats. J. Clin. Invest., v.104, n.10, p.1411-1420, 1999.

MANZANO, J.; MORTE, B.; SCANLAN, T. S.; BERNAL, J. Differential effects of triiodothyronine and the thyroid hormone receptor beta-specific agonist GC-1 on thyroid hormone target genes in the b ain. Endocrinol., v.144, n.12, p.5480-5487, 2003.

MEDINA, R.; WING, S. S.; HAAS, A.; GOLDBERG, A. L. Activation of the ubiquitinATP-dependent proteolytic system in skeletal muscle during fasting and denervation atrophy. Biomed. Biochim. Acta., v.50, n.4-6, p.347-356, 1991.

MITCH, W. E.; GOLDBERG, A. L. Mechanisms of muscle wasting. The role of the ubiquitin-proteasome pathway. N. Engl. J. Med., v.335, n.25, p.1897-1905, 1996.

MITSUHASHI, T.; NIKODEM, V. M. Regulation of expression of the alternative mRNAs of the rat alpha-thyroid hormone receptor gene. J. Biol. Chem., v.264, n.15, p.8900-8904, 1989.

MITSUHASHI, T.; TENNYSON, G. E.; NIKODEM, V. M. Alternative splicing generates messages encoding rat c-erbA proteins that do not bind thyroid hormone. Proc. Natl. Acad. Sci. U S A, v.85, n.16, p.5804-5808, 1988.

MIYABARA, E. H.; AOKI, M. S.; SOARES, A. G.; SALTAO, R. M.; VILICEV, C. M.; PASSARELLI, M.; SCANLAN, T. S.; GOUVEIA, C. H.; MORISCOT, A. S. Thyroid hormone receptor-beta-selective agonist GC-24 spares skeletal muscle type I to II fiber shift. Cell. Tissue. Res., v.321, n.2, p.233-241, 2005.

MOORE, J. M.; GUY, R. K. Coregulator interactions with the thyroid hormone receptor. Mol. Cell. Proteomics, v.4, n.4, p.475-482, 2005.

NAKASHIMA, K.; OHTSUKA, A.; HAYASHI, K. Effects of thyroid hormones on myofibrillar proteolysis and activities of calpain, proteasome, and cathepsin in primary cultured chick muscle cells. J. Nutr. Sci. Vitaminol, v.44, n.6, p.799-807, 1998.

NURY, D., DOUCET, C., COUX, O. Roles and potential therapeutic targets of the ubiquitin proteasome system in muscle wasting. BMC Biochem. v. 8, p.1471-2091, 2007.

PARK, K. C.; KIM, J. H.; CHOI, E. J.; MIN, S. W.; RHEE, S.; BAEK, S. H.; CHUNG, S. S.; BANG, O.; PARK, D.; CHIBA, T.; TANAKA, K.; CHUNG, C. H. Antagonistic regulation of myogenesis by two deubiquitinating enzymes, UBP45 and UBP69. Proc. Natl. Acad. Sci. U S A, v.99, n.15, p.9733-9738, 2002. 
PUCCI, E.; CHIOVATO, L.; PINCHERA, A. Thyroid and lipid metabolism. Int. J. Obes. Relat. Metab. Disord., v.24 Suppl 2, p.S109-112, 2000.

SOARES, A. G; AOKI, M. S.; MIYABARA, E. H.; DELUCA, C. V.; ONO, H. Y.; GOMES, M. D.; MORISCOT, A. S. Ubiquitin-ligase and deubiquitinating gene expression in stretched rat skeletal muscle. Muscle Nerve, v.36, n.5, p.685-693, 2007.

SOLOMON, V.; GOLDBERG, A. L. Importance of the ATP-ubiquitin-proteasome pathway in the degradation of soluble and myofibrillar proteins in rabbit muscle extracts. J. Biol. Chem., v.271, n.43, p.26690-26697, 1996.

TAWA, N. E.; JR., ODESSEY, R.; GOLDBERG, A. L. Inhibitors of the proteasome reduce the accelerated proteolysis in atrophying rat skeletal muscles. J. Clin. Invest., v.100, n.1, p.197-203, 1997.

TIAO, G.; FAGAN, J.; ROEGNER, V.; LIEBERMAN, M.; WANG, J. J.; FISCHER, J. E.; HASSELGREN, P. O. Energy-ubiquitin-dependent muscle proteolysis during sepsis in rats is regulated by glucocorticoids. J. Clin. Invest., v.97, n.2, p.339-348, 1996.

TOGASHI, M.; BORNGRAEBER, S.; SANDLER, B.; FLETTERICK, R. J.; WEBB, P.; BAXTER, J. D. Conformational adaptation of nuclear receptor ligand binding domains to agonists: potential for novel approaches to ligand design. J. Steroid. Biochem. Mol. Biol., v.93, n.2-5, p.127-137, 2005.

TROST, S. U.; SWANSON, E.; GLOSS, B.; WANG-IVERSON, D. B.; ZHANG, H.; VOLODARSKY, T.; GROVER, G. J.; BAXTER, J. D.; CHIELLINI, G.; SCANLAN, T. S.; DILLMANN, W. H. The thyroid hormone receptor-beta-selective agonist GC-1 differentially affects plasma lipids and cardiac activity. Endocrinology, v.141, n.9, p.3057-3064, 2000.

VADASZOVA, A.; ZACHAROVA, G.; MACHACOVA, K.; JIRMANOVA, I.; SOUKUP, $T$. Influence of thyroid status on the differentiation of slow and fast muscle phenotypes. Physiol. Res., v.53 Suppl 1, p.S57-61, 2004.

VALERO, R.; BAYES, M.; FRANCISCA SANCHEZ-FONT, M.; GONZALEZANGULO, O.; GONZALEZ-DUARTE, R.; MARFANY, G. Characterization of alternatively spliced products and tissue-specific isoforms of USP28 and USP25. Genome Biol., v.2, n.10, p.RESEARCH0043, 2001.

WILKINSON, K. D. Ubiquitination and deubiquitination: targeting of proteins for degradation by the proteasome. Semin. Cell. Dev. Biol., v.11, n.3, p.141-148, 2000.

WILLIAMS, G. R. Cloning and characterization of two novel thyroid hormone receptor beta isoforms. Mol. Cell. Biol., v.20, n.22, p.8329-8342, 2000.

WILLIAMS, G. R.; ZAVACKI, A. M.; HARNEY, J. W.; BRENT, G. A. Thyroid hormone receptor binds with unique properties to response elements that contain hexamer domains in an inverted palindrome arrangement. Endocrinology, v.134, n.4, p.18881896, 1994. 
YEN, P. M. Physiological and molecular basis of thyroid hormone action. Physiol . Rev., v.81, n.3, p.1097-1142, 2001.

ZHANG, J.; LAZAR, M. A. The mechanism of action of thyroid hormones. Annu. Ver. Physiol., v.62, p.439-466, 2000. 